\title{
Research on the Construction of Professional Degree Postgraduate Education Faculty
}

\author{
Jinpeng Jiao \\ Harbin University of Commerce, Haerbin, China \\ 114049669@qq.com
}

Keywords: Professional degree graduate; Graduate Education; Faculty construction

\begin{abstract}
In order to promote the development of professional degree postgraduate education, we have carried out active explorations in terms of teacher equipment, teacher team building, teacher team training, and dynamic evaluation of the teaching staff. However, there are still some problems in the construction of professional degree postgraduate education teachers to constantly improve, realizing the construction of the teaching staff as the focus and promoting the construction of professional degree graduate education teachers.
\end{abstract}

Professional degree postgraduate education is set up with the rapid development of modern science and technology and society, aiming at the needs of specific occupational fields, and cultivating high-level applied professionals with strong professional competence and professionalism and capable of creatively engaging in practical work. Professional degrees have a relatively independent educational model with specific professional orientation, which is a high degree of professional and academic unity. In the era of globalization, knowledge is changing with each passing day, competition and technological revolution are everywhere. It is urgent for graduate education to cultivate a large number of high-level applied and compound talents who are creative and independent, can adapt to the changes of the times, and master new technologies to meet the industrial sector. And the needs of the application department to implement the strategy of rejuvenating the country through science and education. Therefore, cultivating a faculty team that meets the professional degree postgraduate education is the key to ensuring the quality of the training.

\section{The status quo of the construction of professional degree postgraduate education teachers}

In order to realize the rapid development of professional degree postgraduate education, detailed training programs have been formulated in the training objectives, training mode, curriculum, teaching concept, teaching methods and practical teaching of professional degree graduates, especially in the construction of teaching staff.

\subsection{Faculty team}

In order to improve the teaching quality of professional degree graduates and promote the sustainable development of professional degree graduate education, it is necessary to take effective measures to increase the training of teachers, so that the professional degree graduate teachers are both "learning" and "surgery". "The top of the earth" has both theoretical level, the most advanced and cutting-edge theoretical knowledge, and based on social practice, with solid practical skills.

Develop reasonable selection criteria for classroom teachers. The teacher selected to adhere to the principle of "standard standards, strict procedures, fairness and justice, and lack of indiscriminateness". In view of the particularity of professional degree graduate training, selected teachers should have modern educational concepts, rich teaching experience, strong social practice experience, and at least two instructors should be equipped in the core curriculum and professional direction. 
Integrate outstanding teachers and teachers inside and outside the school, expand the source channels of professional degree graduate teachers, and build a team of teachers with special and part-time work. Integrate the best teachers from relevant colleges and related majors to expand the knowledge and supply of nutrients for professional degree graduates to ensure stable and high-quality operation.

Off-campus experts, entrepreneurs, and government officials. Engage experts, entrepreneurs and government officials from relevant fields to teach, lecture or hold forums for professional degree graduates, and issue employment certificates for experts in relevant fields to establish a long-term mechanism to achieve the vision and vision of the students and share the theory and practice of success. Experience, enrich the purpose of the students' experience outside the classroom.

\subsection{Teacher training}

Encourage and actively create conditions to train teachers, support teachers to participate in further studies, training, course seminars, case seminars, academic conferences, exchanges and studies between schools, and in-depth study of enterprises and government agencies. In addition, the teaching team regularly organizes and conducts teaching research activities to promote the exchange of teaching methods and the improvement of teaching effects.

\subsection{Faculty team construction}

In order to ensure the development of professional degree education, there is sufficient teacher strength to match, and gradually promote the echelon construction of professional degree education teachers. Each course, equipped with two teachers, can ensure the smooth progress of the course, and can also set up a course construction team to ensure the quality of the course.

\subsection{Dynamic evaluation of the teaching staff}

In order to improve the teaching level of the teaching staff, dynamic evaluation and management mechanisms have been activated. The teaching effect is evaluated and feedback in a phased manner and a combination of multiple evaluation methods. The so-called phased, The first stage is to evaluate and feedback the teaching effect of the teachers in this semester at the end of each semester. Second, after all the courses are finished, feedback on the course system, the quality of the lectures, and the overall teaching results. A variety of evaluation methods refer to the use of seminars, personal feedback, questionnaires, etc., all aspects, multi-angle evaluation of teaching effects, and promote the continuous improvement of teaching quality and teaching level. To enable students to comprehensively evaluate teachers in terms of teaching effects and practicality of teaching content, to achieve dynamic management of classroom teachers, so that instructors can timely understand the teaching situation, improve teaching methods, and train high-quality professional degree graduates. Lay the foundation.

\section{Problems in the construction of professional degree postgraduate education teachers}

China's professional degree postgraduate education started late compared with foreign professional degree postgraduate education. Due to the full support of college teachers, it has achieved great success in a relatively short period of time. However, because the measurement standard of professional degree postgraduate education quality is different from the measurement standard of academic degree postgraduate education quality, the existing teaching staff engaged in professional degree postgraduate education cannot fully meet the requirements of professional degree postgraduate education.

\subsection{Lack of faculty dedicated to professional degree graduate education}

At present, most of the faculty members of professional degree postgraduate education rely on the faculty of various universities to share a set of faculty with undergraduate teaching and academic postgraduate education in colleges and universities. The lack of a full-time faculty for professional 
degree graduate education has greatly affected the quality of professional degree graduate education and restricted its development.

\subsection{Teaching methods and methods are outdated and do not meet the training requirements for professional degree graduate education}

Since there is no obvious distinction between the faculty of cultivating professional degree graduates and the faculty of undergraduate and academic degree graduates, teachers will train the teaching methods and methods of undergraduate and academic degree graduates in the course of teaching. In the middle, the teaching mode of professional degree postgraduate education is basically consistent with the mode of academic postgraduate teaching. Most of them adopt the teacher-centered theory and teaching method. Students can't realize the combination and transformation of theory and practice, and can't really solve the problems in practical work, so it is difficult to achieve the goal of cultivating professional degree graduate students. It makes the theory and practice not enough, the teaching method is single, the teaching effect is not good, the teaching efficiency is not high; the case discussion, practice teaching and other links are weak, and it is impossible to cultivate students' creative thinking and application ability.

\subsection{Lack of systematic practical teaching training, resulting in the lack of teachers with} industry practical experience

At present, the faculty engaged in professional degree education is mainly teachers who are engaged in academic degree teaching at universities. They are good at cultivating professional graduate students in the way of cultivating academic graduate students, following the "college-style" talent training model. Teaching to teaching, focusing on theory and practice. Due to the lack of systematic practical teaching and training, teachers lack practical experience in specific industries, can not combine theory and practice perfectly in teaching, and have no rich practical experience and students to share.

\section{Countermeasures for the Construction of Professional Degree Postgraduate Education Faculty}

3.1 Cultivate full-time teachers and establish a full-time professional postgraduate education faculty to ensure the effective development of professional degree postgraduate teaching

A full-time professional degree postgraduate education faculty with high academic content, obvious professional background, rich practical experience and strong problem-solving ability is the key factor to ensure the quality of professional degree education, and also the sustainable development of professional degree education. The fundamental guarantee. Only with a full-time faculty team can we truly realize the training mode of building a high-level faculty team with the theory, case development, scientific research and the practice of enterprises and institutions. Allowing teachers to have sufficient time and energy to teach relevant basic theories for professional degree graduates, to go deep into enterprises and institutions, and to conduct on-the-spot investigations, not only enables students to better combine theory with practice, but also enables teachers to obtain useful materials. Carry out case development and scientific research, and at the same time, be able to extract essence from practice docking, carry out case analysis contest and enterprise marketing planning contest.

\subsection{Further strengthen the training of the teaching staff and comprehensively change the teaching methods and methods of the teaching staff}

Develop a scientific professional degree graduate teacher training program to effectively enhance teachers' practical ability. Encourage teachers to participate in relevant domestic teaching and training meetings, broaden their horizons, improve their academic level and innovative ability, master modern teaching methods, and promote teachers' transformation of the teaching methods of 
professional degree graduates from knowledge transfer to ability training and practical application; In the process of teaching, communicate with students with business management experience to enrich the practical knowledge of teachers; in addition to teaching, select teachers to enter the enterprise or institution to learn and realize the connection between the theory and practice of teachers, and submit at least one as an internship result. A complete and practical teaching case that can be used for course teaching.

Actively carry out international exchanges of teachers. Under the circumstances and conditions, organize teachers to conduct international study and exchanges, learn advanced training experience of famous universities, so that the teachers not only have doctoral degrees, but also have profound and broad theoretical knowledge, and have rich practical experience.

\subsection{Conduct systematic practical teaching training and enhance the industry practice experience of the teaching staff}

Only with a full-time faculty can we plan to arrange teacher training, select teachers to work in relevant professional departments, gain practical work experience, develop a domestic and international visiting scholar system, and optimize the knowledge structure of professional degree education teachers. Make the knowledge structure of the faculty team rational and scientific, and integrate relevant industry practical experience to achieve an overall improvement of the overall level of the professional degree education faculty.

\section{References}

[1] Deng Zhiying, Huang Yi.The Status Quo, Problems and Countermeasures of Professional Master's Degree Teaching Staff-Taking the Master Degree of Agricultural Extension as an Example[J].Journal of Hunan Institute of Engineering(Social Science Edition),2014(2):105-109.

[2] Zhu Xiaoyun, Yang Chao promote Teaching Staff in professional degree graduate education research [J].Education Development Research, 2012, 32 (2):104-108.

[3] Wang Hong,Zeng Fusheng,Dong Bo.On the Construction of Professional Degree Education Faculty Team[J].Journal of Nanyang Teachers College,2011,10(2):97-99.

[4] Li Yanfang, but Zhao Bin. Research on the Construction of Teaching Staff for Master of Education in China [J]. Educational Research, 2002(12): 65-69.

[5] Wu Wenli, Zhai Zhihui. Preliminary Study on the Construction of Teaching Masters for Master of Education [J]. Research on Higher Teacher Education, 2000(03):12-16. 